\title{
Pesticide lung: a pilot investigation of fruit-growers and farmers during the spraying season
}

\author{
S LINGS
}

From the Department of Pulmonary Medicine, Odense University Hospital, Denmark

ABSTRACT A fruit-grower with large, atypical lung infiltrations and lung fibrosis triggered off an investigation of fruit-growers during the spraying season. An interview was carried out together with a Wright peak flow meter test and an $x$-ray examination of the chest. No fewer than 156 spray preparations were used by the group; individual fruit-growers used between three and 27. In connection with spraying, $41 \%$ of subjects had one or other type of symptom; peak flow was reduced in $19 \%$ and $x$-ray changes were seen in $24 \%$. A questionnaire was returned by 132 of 235 farmers. Of these, 60 had worked with biocides, 72 had not. A non-significant higher frequency of symptoms was found among those who used biocides. The results would indicate that biocides (or "pesticides") can give rise to a lung disease, "biocide lung," which comprises (1) pneumonia, radiologically demonstrable by more or less transient round infiltrations and (2) chronic progressive lung fibrosis.

The over-all acute toxicity of most biocides (or pesticides) is well-known, but the chronic effects on the respiratory tract are poorly documented, as are their effects on the human organism as a whole, apart from a few exceptions such as DDT. This is rather remarkable, considering the vast quantities of such compounds in daily use.

Fruit-growers in particular are regularly exposed to contact with many different spraying compounds, and repeated inhalation of these, in larger or smaller quantities, is unavoidable. As these products are highly reactive biochemically, it is not difficult to imagine that repeated exposure might be harmful.

\section{Case history}

A 52-year-old man had been a fruit-grower for many years. He suffered periodically from a cough with yellowish sputum; these symptoms were especially pronounced when working with spraying compounds. In addition, he complained of a poor appetite and unintentional loss of $10 \mathrm{~kg}$ in weight during the past two years. He owned about seven acres of land with fruit trees which he himself regularly sprayed about 18 times a year with inadequate protection; he usually used "something like a mask," which was in fact home-made. During the spraying season he often felt poorly and "was unable to get well" between these periods. It is stated that

Received 27 April 1981

Accepted 27 January 1982 during the last months before being referred to hospital, he had used at least 12 different spray compounds, containing the following nine active ingredients: oxydemethon-methyl, paraquat, diquat, benomyl, captofol, captan, azinphos-methyl, parathion, and carbaryl. He smoked 10 cigarettes a day as well as a packet of pipe tobacco a week.

After some five months of lassitude and increasing dyspnoea in the spring of 1974 he was treated at home with penicillin because of an increased temperature, and was referred to the lung clinic, where on $x$-ray examination atypical infiltrations were found in both lungs (fig 1 ).

The patient was admitted to the department of pulmonary medicine two weeks later for further examination. His temperature, however, had returned to normal by this time and the infiltrations in the right lung had been considerably reduced, but the infiltrations in the left lung were unchanged. He was slightly aged, thin, but with no resting dyspnoea or cyanosis. His fingernails were slightly bowed and the thorax somewhat barrel-shaped. Auscultation of the lungs showed low-lying borders and a hollow percussion tone, while the respiratory sounds were weak over both fields with a few rales. The heart sounds were weak due to overlying lung. The abdomen was lean without palpable masses. There was no oedema of the hands or feet.

No abnormality could be found by means of bronchoscopy and mediastinoscopy, including microscopy of the lymph nodes. Tomography of the hilus 


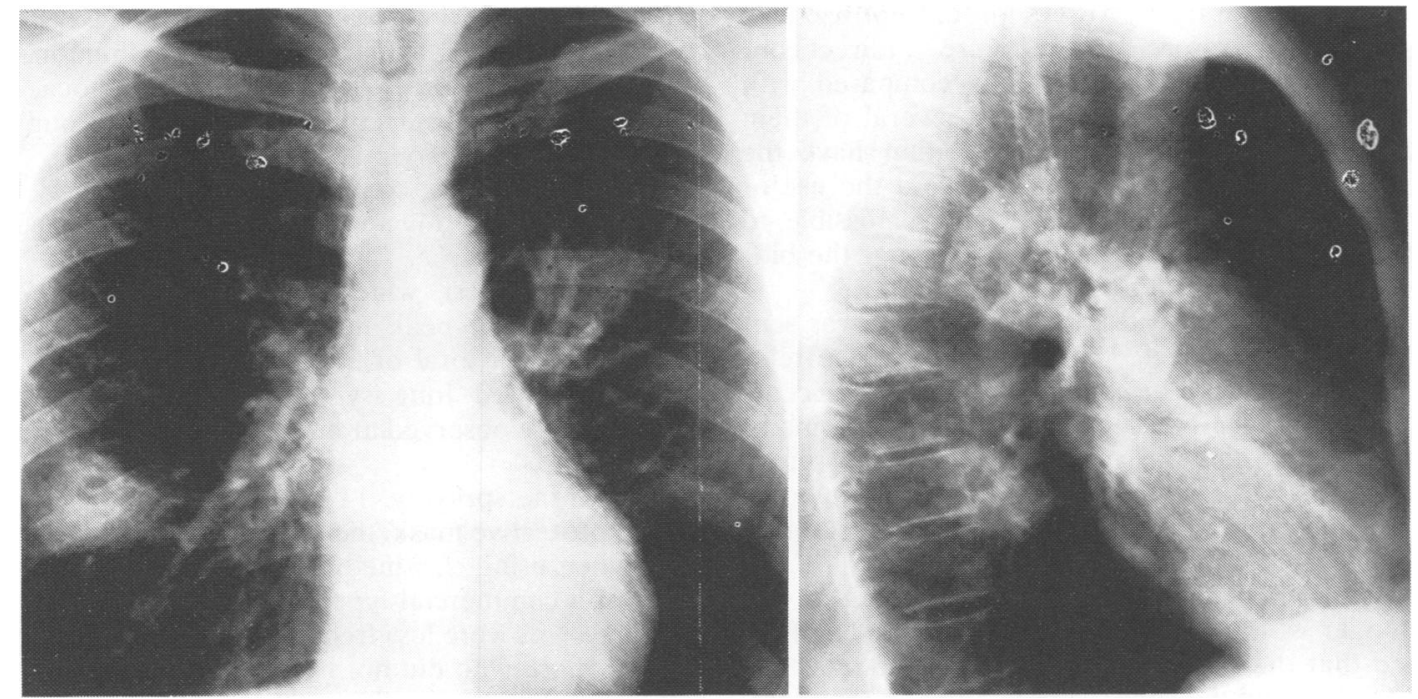

Fig 1 Chest $\mathrm{x}$-ray picture when referred. Right side: an approximately $5 \times 5 \mathrm{~cm}$ large condensation behind the fifth and sixth ribs is seen, with a $1 \frac{1 / 2}{1} \times 1 \frac{1 / 2}{\mathrm{~cm}}$ large clearing up at $12 o^{\prime}$ clock. Left side: a similar condensation with indistinct limitations measuring $41 / 2 \times 4 \mathrm{~cm}$ situated medially in the second intercostal space.

regions showed possible right-sided adenitis. Lung function tests showed obstructive and slight restrictive ventilatory insufficiency $\left(\mathrm{FEV}_{1} 1650\right.$, normal value $3130 \mathrm{ml}$ ). The sputum contained yeasts but no tumour cells or acid-fast bacilli; eosinophilia could not be shown. The results of other laboratory tests were as follows: ESR $13 \mathrm{~mm}$, haemoglobin, leucocytes (including eosinophils), liver function tests, and acid phosphatases were all normal. Alpha-1antitrypsin 1.73 (normal range: 0.68-1.42), ECG showed incomplete right bundle-branch block. The patient was discharged for continued treatment with salbutamol tablets.

He was kept under observation at regular intervals after discharge. A month later the infiltrations had disappeared, leaving a few fibrotic strands, but the symptoms of bronchitis were still present and accompanied by increasing dyspnoea. The patient gave up his occupation shortly afterwards and was awarded a disability pension.

At the last $x$-ray examination five years after admission, the thorax had a somewhat emphysematic appearance and there were now pronounced spotted and streaky changes in the central lung fields indicating severe fibrosis.

This case triggered off a pilot investigation of fruit-growers during the spraying season.

\section{Present investigation}

MATERIAL AND METHODS

A questionnaire, together with an invitation to attend the lung clinic for a more thorough investigation in June, was sent out in the spring of 1975 to all members on Funen of the Danish Fruit-growers Association. The object of the invitation to attend the clinic in June was that at this time the spraying is in full progress or has just been completed. A total of 318 invitations was sent out and 188 people (59\%) responded; seven had to be excluded because of incomplete examinations, insufficient information, or because they had not worked with spraying compounds for some time.

The fruit-grower cohort thus comprises 181 "responders" (group R) all men, who returned the questionnaire and who underwent a Wright peak flow meter test and $x$-ray examinations. The median age of the group was 49 (range 19-74).

Those who did not respond to the invitation were later asked to fill in and return a short questionnaire regarding symptoms. A total of 118 replies were received; 10 of the growers had never participated in spraying, 13 were no longer active fruit-growers, and two questionnaires were incomplete and could not be used. The relatives of five replied that the person to whom the questionnaire had been sent had died. The remaining 93 "non-responders" (group N-R) were all men with a median age of 51 (range 23-84). They did not differ in respect of age from the 181 who had primarily responded to the invitation (group R). Thus information was obtained from a total of $311(97 \cdot 8 \%)$.

It has not been possible to compile a relevant control group of people who worked under the same 
conditions as the fruit-growers but did not use biocides. It was therefore decided to use "indirect controls"; farmers cannot be directly compared with fruit-growers (see discussion), but several of them work with biocides, while others either have the spraying done by a contractor or avoid the use of these chemicals entirely. It should be possible to obtain an impression of the importance of the biocide burden by comparing such groups.

Therefore in July 1981 a questionnaire was sent to $\mathbf{2 3 5}$ farmers, selected at random from the telephone book in such a manner as to give an acceptable geographical distribution; this questionnaire contained questions as to the occurrence of symptoms during the previous month. Of the $136 \mathrm{com}$ pleted questionnaires returned, four had to be discarded owing to incomplete answers or because the person to whom the form had been addressed was no longer working as a farmer. The relatives of six stated that the person had died. Thus the response was $60.4 \%$, and the cohort consisted of 132 farmers, all men, with a median age of 59 (range 23-89).

\section{Results}

\section{FRUIT-GROWERS}

No fewer than 156 various commercial spray products containing 92 active ingredients were used. Each individual had used between three and 27 different sprays, on average 13.

Those most often used were, in descending order: captan (fungicide), paraquat (weed-killer), parathion (insecticide), azinphos-methyl (insecticide), diquat (weed-killer), amitrol (weed-killer), benomyl (fungicide), and simazin (weed-killer).

Seventy-eight $(43 \%)$ of group R and $33(35 \%)$ of group N-R had one or other type of symptom in connection with the spraying (table 1). Sixty-one (22\%) had two or more symptoms. Pulmonary symptoms (coughing, expectoration, dyspnoea, or a combination) occurred in $35(19 \%)$ in group $R$ and $14(15 \%)$ in group N-R, 11 had all three.

None of the spray compounds could definitely be said to trigger off any special symptoms to any particularly high degree.

The Wright test, which was carried out in 178 , showed that the peak flow was reduced by more than $10 \%$ in a total of 33 cases $(18.5 \%)$; nine of these presented lung symptoms. Relevant $x$-ray changes were observed at the same time in 10 (table 2).

During the spraying, 111 of group $\mathbf{R}$ had always used a protective mask, the great majority, however, only when using classified poisons. The masks used were of a commercial type. Symptoms and positive physical signs were less frequent in these individuals than in those who did not use a mask during spraying (table 2), but the difference is not significant.

Only diffuse accentuation of the pulmonary markings and infiltrations were considered radiologically relevant while, for instance, cases with isolated "older" fibrotic strands and calcifications were excluded. "Relevant" radiological changes were found in a total of $43(23.8 \%)$ and of these, accentuation of pulmonary markings occurred in $\mathbf{4 0}$ and infiltrations in 10, while seven had both (table 2). No larger atypical infiltrations, as described in the case history, could be shown. After primary survey examination, 15 were requested to attend the clinic for further $x$-ray or other examinations. Ten of these will be described in more detail.

Case 1

A 68-year-old man, a fruit-grower for 25 years, had

Table 1 Occurrence of symptoms among fruit-growers according to frequency. Group $R$ was examined at a lung clinic, group $N-R$ only answered a questionnaire. Differences are not significant

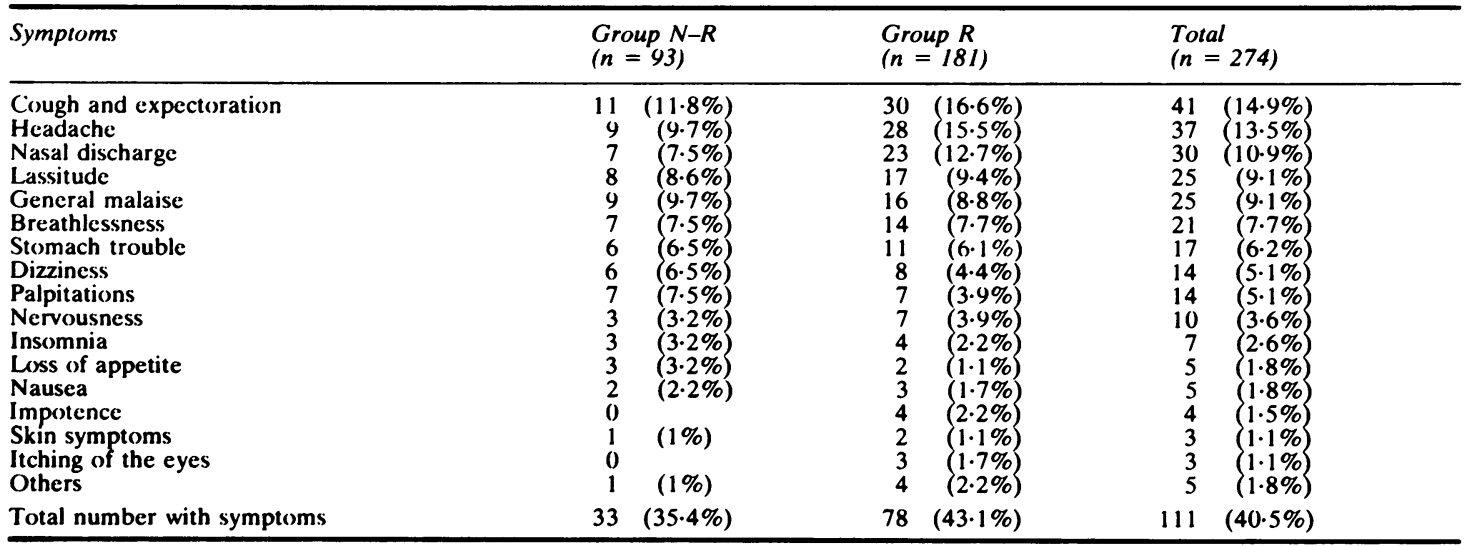


Table 2 Combination of symptoms and objective findings as well as the effect of a mask. The differences between the first two columns are not significant

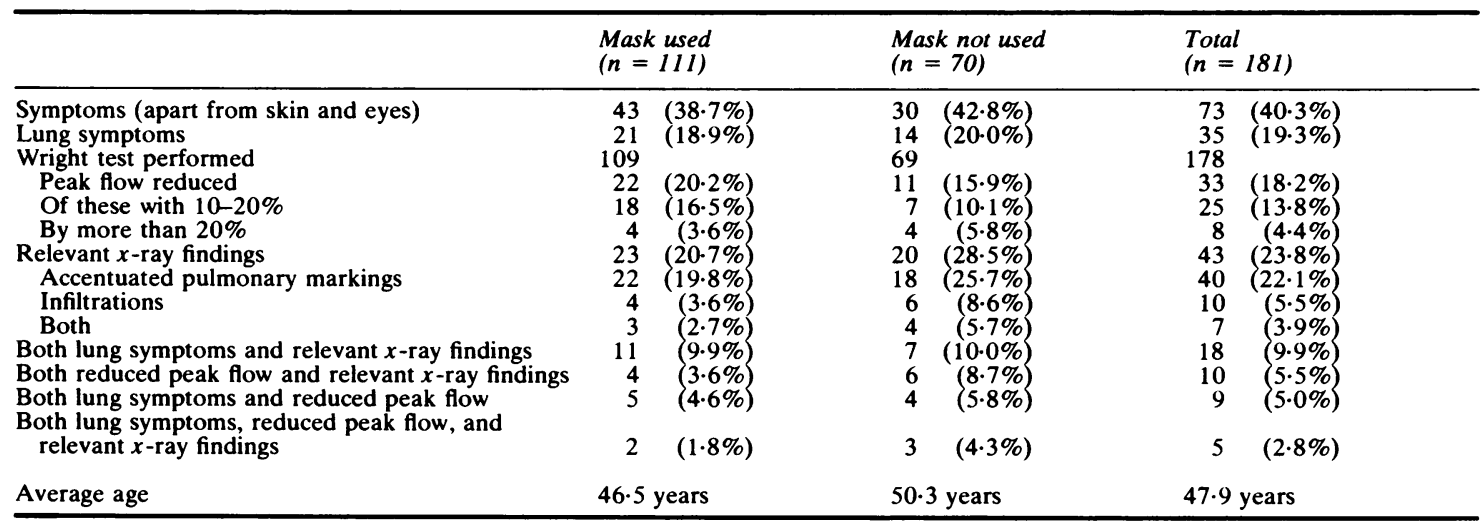

been examined for the last time some three years previously, when no abncrmality had been found. The present investigation showed diffuse accentuation of pulmonary markings, particularly basally; these were interpreted as lung fibrosis. The patient felt well apart from feeling dizzy during the spraying season and had, during the past 10 years, suffered an unintentional loss of weight of about $10 \mathrm{~kg}$. As to spray compounds he had most often used thiram, but had used at least 22 others. He usually used a commercial mask during work with classified poisons.

He was kept under ambulatory control and began to complain of dyspnoea during the following months. During an influenza-like episode 10 months after the initial examination the symptoms became worse and he also developed a cough, most pronounced in the morning, with varying amounts of expectoration, and accompanied by chest and back pain. He was admitted to the department of pulmonary medicine for more thorough examination.

Physical examination showed no noteworthy abnormalities, apart from crackles over the lower part of both lungs, on both the anterior and posterior surfaces. There were no changes in the nails. Lung function tests were carried out twice, including the diffusion test, which gave normal results despite widespread radiological changes.

Tubercle bacilli could not be seen and all the laboratory tests gave normal results (including alpha-l-antitrypsin and the rheuma tests) apart from antinuclear factors, which was positive $(+)$. The patient was discharged in good health without having received treatment but was kept under continued observation. The symptoms gradually worsened. In particular, he complained of hour-long attacks of coughing and dyspnoea and was therefore again admitted to hospital 18 months later. The lung function test now showed restrictive ventilatory insufficiency with an FEV of $1750 \mathrm{ml}$ (normal 2440). Laboratory tests showed ESR: $36 \mathrm{~mm}$, lactic dehydrogenase and basic phosphatase slightly increased, otherwise no abnormality. He was treated in the traditional manner and again discharged. His condition continued to deteriorate, both clinically and radiologically, and cardiac enlargement developed. During admission to hospital six months later (when the basic phosphatase was still slightly increased) treatment was started with prednisone, with transitory effect, but in the autumn of 1979 the patient died with a clinical picture of combined lung and heart insufficiency. The relatives refused to permit postmortem examination.

\section{Case 2}

This 50-year-old man had worked with at least 19 different spray compounds without using a mask; however, there were no symptoms. The $x$-ray examination showed a small round infiltration in the right lower lobe. The peak flow was reduced by $10 \%$. The infiltration decreased in size during the following months and had completely disappeared six months later. The only radiological finding thereafter was "enhanced pulmonary vascular markings in the right lower field." Five years later there were still no symptoms, and radiological examination of the chest showed no abnormality.

\section{Case 3}

A 36-year-old man who had worked with at least 10 spray compounds without using any protection complained of lassitude and "stomach trouble" during the spraying season. The Wright test was normal. A radiological examination showed a round condensation immediately laterally to the right hilus, but this was not visible some three months later. 
Case 4

A 51-year-old man, who had used at least nine spray compounds but with no mask, was free from symptoms at the time of examination, but suffered from attacks of asthma. The Wright test was normal. $X$-ray examination showed considerable accentuation of the pulmonary markings on both sides, as well as enlarged hili. The lung function test showed no definite abnormality. At the last control examination three years later, his condition was unchanged, both clinically and radiologically.

\section{Case 5}

A 52-year-old man who had worked with 14 different spray compounds and had used a mask during the use of classified poisons complained of coughing and loss of breath. The Wright test was normal. $X$-ray examination showed slightly increased pulmonary markings bilaterally, as well as a round infiltration at the apex of the heart. The latter decreased in size gradually and five months later had completely disappeared.

\section{Case 6}

This 62-year-old man stated that he used only three different spray compounds. He was free from symptoms at the time of examination, but a short time previously he had been treated at home for "pneumonia." The Wright test was reduced by $20 \%$. $X$-ray examination showed a rounded infiltration in the left lung field; this had been replaced two months later by condensed streaks, which after a further month had disappeared. After five years he complained of increasing dyspnoea, but a chest $x$-ray examination showed no abnormality, apart from slight enlargement of the heart.

\section{Case 7}

A 37-year-old man, who during the spraying season had worked with 20 different compounds and "only partly" used a mask, complained of coughing and nasal blockage. The Wright test was normal. $X$-ray examination showed accentuation of the pulmonary markings in both lower fields and, on the left side, an irregular condensation, which at the re-examination two and a half months later had been replaced by a fibrotic strand. $X$-ray examination three years later showed no abnormality.

\section{Case 8}

This 37-year-old man had worked with eight different spray compounds and usually used a mask, but owing to difficulty in breathing inserted only one of the two recommended filters. No symptoms; normal Wright test, but $x$-ray examination showed a cystlike structure in the third left intercostal space; this could not be seen during more thorough examination three months later.

\section{Case 9}

A 31 -year-old man who had been in contact with 21 various compounds but who had not used a mask was free from symptoms. The Wright test was normal, but $x$-ray examination showed a round shadow in the fifth left intercostal space which had disappeared two months later.

Case 10

A 57-year-old man, who had worked with 14 different spray compounds and who had not used a mask, complained of coughing, nasal blockage and breathlessness, lassitude, general malaise, headache and insomnia. The Wright test was reduced by $25 \%$. $X$-ray examination, including tomography, showed considerable fibrotic strands in the major portion of the lungs on both sides, and several large cysts (about $2 \times 3 \frac{1}{2} \mathrm{~cm}$ ) in the right lung; there was also a suspicious area suggesting a smaller cyst in the left apex. His condition was, on the whole, unchanged five years later.

Table 3 shows the symptoms and positive findings in the users of paraquat in group $\mathrm{R}$ as compared with non-users. The figures indicate a more frequent occurrence of lung affection in users of paraquat. without, however, there being any greater significance. An attempt has also been made to evaluate the relative toxicity of other compounds. but the results were ambiguous.

\section{FARMERS}

Sixty farmers stated that they had actually worked with spray compounds (group FB), while 72 had not done so (group F). The age distribution of these two groups is shown in fig 2 . The median age for group

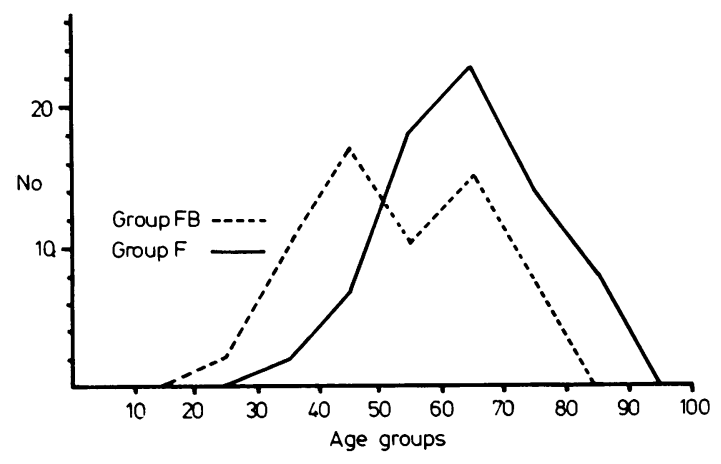

Fig 2 Age distribution of the wo groups of farmers. Graphs pass through middle point of 10 -year age classes. Group FB: biocides used. Group F: biocides not used. 
Table 3 Relative toxicity of paraquat

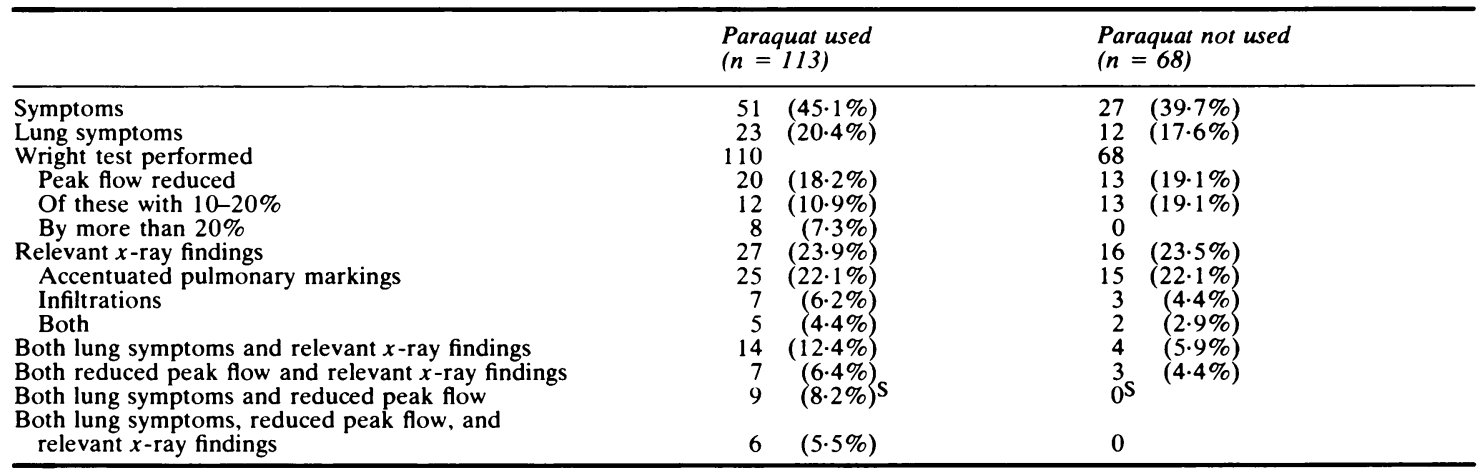

$\mathrm{S}$ indicates significance at the $5 \%$ level (Fisher's exact test).

Table 4 Symptoms in farmers according to frequency. The differences are not significant

\begin{tabular}{llll}
\hline & $\begin{array}{l}\text { Biocides } \\
\text { used } \\
\text { (group FB) } \\
(n=60\end{array}$ & $\begin{array}{l}\text { Biocides } \\
\text { not used } \\
(\text { group } F) \\
(n=72)\end{array}$ & $\begin{array}{l}\text { Total } \\
(n=132)\end{array}$ \\
\hline Lassitude & $20(33 \%)$ & $15(21 \%)$ & $35(27 \%)$ \\
Breathlessness & $13(22 \%)$ & $13(18 \%)$ & $26(20 \%)$ \\
Nasal discharge & $8(13 \%)$ & $11(15 \%)$ & $19(14 \%)$ \\
Headache & $11(18 \%)$ & $7(10 \%)$ & $18(14 \%)$ \\
Cough and expectoration & $8(13 \%)$ & $9(13 \%)$ & $17(13 \%)$ \\
Insomnia & $7(12 \%)$ & $10(14 \%)$ & $17(13 \%)$ \\
General malaise & $8(13 \%)$ & $7(10 \%)$ & $15(11 \%)$ \\
Dizziness & $4(7 \%)$ & $8(11 \%)$ & $12(9 \%)$ \\
Nervousness & 5 & 7 & 12 \\
Stomach trouble & 5 & 5 & 10 \\
Palpitations & 3 & 3 & 6 \\
Nausea & 3 & 3 & 6 \\
Impotency & 2 & 2 & 4 \\
Loss of appetite & 1 & 0 & 1 \\
\hline
\end{tabular}

Table 5 Farmers distributed by pulmonary symptoms and by no symptoms at all. The differences are not significant

\begin{tabular}{llll}
\hline & $\begin{array}{l}\text { Biocides } \\
\text { used } \\
\text { (group FB) } \\
(n=60)\end{array}$ & $\begin{array}{l}\text { Biocides } \\
\text { not used } \\
(\text { group F) } \\
(n=72)\end{array}$ & $\begin{array}{l}\text { Total } \\
(n=132)\end{array}$ \\
\hline No symptoms & $30(50 \%)$ & $41(57 \%)$ & $71(54 \%)$ \\
Symptoms & $30(50 \%)$ & $31(43 \%)$ & $61(46 \%)$ \\
Pulmonary symptoms & $17(28 \%)$ & $17(24 \%)$ & $34(26 \%)$ \\
\hline
\end{tabular}

Table 6 Major frequencies in fruit-growers and farmers

\begin{tabular}{lll}
\hline & $\begin{array}{l}\text { Fruit-growers } \\
(n=274)\end{array}$ & $\begin{array}{l}\text { Farmers } \\
(n=132)\end{array}$ \\
\hline Cough and expectoration & $41(14.9 \%)$ & $17(12.9 \%)$ \\
Headache & $37(13.5 \%)$ & $18(13.6 \%)$ \\
Nasal discharge & $30(10.9 \%)$ & $19(14.3 \%)$ \\
Lassitude & $25(9.1 \%)$ & $35(26.5 \%)$ \\
General malaise & $25 \quad 9.1 \%) s$ & $15(11.4 \%) s$ \\
Breathlessness & $21(7.7 \%) s$ & $26(19.7 \%) s$ \\
\hline
\end{tabular}

$S$ means Significant difference (Chi square test, $\mathrm{p}<0.001$ ).
FB is 50 (range 23-73), and for group F 64 (range 34-89).

The distributicn of the answers is shown in tables 4 and 5.

A few of the participants complained, in an accompanying letter, of their working conditions. Thus one wrote as follows: "Farmers with large herds of cattle in poorly ventilated cowsheds will, after working in the stable in ammonia-saturated air, recognise the symptoms mentioned. An increase in the severity of symptoms can be observed during the actual 'spraying season' when herbicides are used, and later especially during the use of organic phosphate compounds for insect control."

The age composition of the two groups differed considerably. The younger farmers used chemicals to a far greater extent than the older farmers. The reasons for this may be, among other things, that the older farmer has a somewhat more sceptical attitude towards using chemicals, and the younger farmer may be forced owing to the difficult financial times to use all available methods to increase agricultural output.

Further, it is remarkable that more farmers $(46 \%)$ than fruit-growers $(40.5 \%)$ suffered from symptoms, despite the fact that all the fruit-growers used spray compounds. The difference, however, is not significant. On the other hand, the farmers complained, in the main, of tiredness (fatigue) and of being "out-of-breath," while the most frequent complaints of the fruit-growers were coughing and expectoration as well as headache. The frequency of symptoms is compared in table 6 . There is a significant difference in the frequencies of both fatigue and dyspnoea, presumably because the farmer has a more physically tiring job than the fruit-grower; the differences in the other frequencies are insignificant. 


\section{Discussion}

Several of the biocides are fatal poisons in small doses. Paraquat, at least, is known to be toxic to the lung when swallowed, ${ }^{1}$ just as it possesses a pronounced general toxicity and, among other things, causes injury to the kidneys, liver, and myocardium. The intake of larger doses rapidly produces fatal oedema of the lung and haemorrhage, while the consumption of smaller doses can cause progressive respiratory insufficiency starting several days later. Diffuse lung infiltrations may be observed on the $x$-ray pictures. Pathoanatomically, in these cases, one may observe remarkably early severe alveolar and interstitial fibrosis, as well as oedema, haemorrhage, hyaline membranes, and proliferation of the alveolar epithelium..$^{2-4}$ Apparently the changes continue to progress when the concentration threshold has first been surpassed. ${ }^{5}$ Paraquat mainly accumulates in the lungs and is specifically bound to lung tissue. ${ }^{67}$ Seidenfeld $e a^{8}{ }^{8}$ could bring about pathoanatomical changes, as those above, including fibrosis, in rabbits by having them inhale a paraquat aerosol. The rat lung seems to be less susceptible. ${ }^{9}$

Lung fibrosis can be seen in, among other conditions, pneumonoconiosis and in connection with the intake of certain drugs. It has not been possible, despite a thorough search of publications, to find case histories such as those reported here which have been related to the effects of biocides, but it is reasonable to assume that there is a relationship, even though other diagnostic possibilities are, of course, present.

The fruit-growers, who participated in the present investigation, used respiratory protection to some extent. A mask was used by $39 \%$ and the others stated that they always remained inside an enclosed tractor cabin and always drove to the windward side during spraying.

The work-stress burden on the farmer varies considerably and is often severe-dust, biogases such as $\mathrm{CO}_{2}, \mathrm{NH}_{3}, \mathrm{H}_{2} \mathrm{~S}$, and $\mathrm{CO}$, "animal-emanation," chemicals, vibration from rolling stock, and extreme variations in temperature. ${ }^{1011}$ To this must be added the hard physical work as well as the risk of accident. The symptoms occurred slightly more often in the group (FB) using biocides, even though this group comprised the youngest participants, but none of the differences was significant. This possibly results from the air pollution of farmers being so complex that only large cohorts will be able to show the importance of single factors. If the two groups are made similar with regard to age the differences between the frequencies of symptoms increases slightly but still diverge more and more from the limit of significance owing to the groups becoming smaller (41 in each).

If the number of different spray compounds used appears vast the register of pesticides classified for sale by the Danish Toxicological Board is overwhelming. ${ }^{12}$ This includes far more than $1000 \mathrm{com}$ mercial preparations and more than 450 various chemical compounds, the biological effect of which, in the long term, is unknown.

\section{Conclusion}

This investigation seems to indicate that the professional use of biocides can give rise to a lung disease, biocide lung, which comprises (1) pneumonia, radiologically demonstrable by more or less transient, round infiltrations and (2) chronic progressive lung fibrosis. No definite protective effect could be shown from the use of a face mask.

\section{References}

' Raffin TA, Robin ED. Paraquat ingestion and plumonary injury. West J Med 1978;128:26-34.

${ }^{2}$ Copland GM, Kolin A, Shulman HS. Fatal pulmonary intraalveolar fibrosis after paraquat ingestion. $N$ Engl $J$ Med 1974;291:290-2.

${ }^{3}$ Smith P, Heath D, Kay JM. The pathogenesis and structure of paraquat-induced pulmonary fibrosis in rats. $J$ Pathol 1974;114:57-67.

4 Smith P, Heath D. Paraquat lung: a reappraisal. Thorax 1974;29:643-53.

${ }^{5}$ Rebello G, Mason JK. Pulmonary histological appearances in fatal paraquat poisoning. Histopathology 1978;2:53-66.

- Smith LL, Wright A, Wyatt I, Ross MS. Effective treatment for paraquat poisoning in rats and its relevance to treatment of paraquat poisoning in man. $\mathrm{Br}$ Med J 1974;iv:569-71.

${ }^{7}$ Rose MS, Lock EA, Smith LL, Wyatt I. Paraquat accumulation: tissue and species specificity. Biochem Pharmacol 1976;25:419-23.

seidenfeld JJ, Wycoff D, Zavala DC, Richerson HB. Paraquat lung injury in rabbits. Br J Ind Med 1978;35:245-57.

' Wyatt I, Doss AW, Zavala DC, Smith LL. Intrabronchial instillation of paraquat in rats: lung morphology and retention study. Br J Ind Med 1981;38:42-8.

${ }^{10}$ Donham KJ, Rubino M, Thedell TD, Kammermeyer J. Potential health hazards to agricultural workers in swine confinement buildings. JOM 1977;19:383-7.

$"$ Cliffs KS. Agriculture-the occupational hazards. Public Health 1981;95:15-27.

12 Danish Toxicological Board. Register of pesticides classified for sale 1980. Copenhagen: DTB, 1980. 